\title{
COMPLEX SYSTEM OF THE SOLID WASTE MANAGEMENT IN CITY
}

\author{
Vadim S Tchekalin \\ St Petersburg State Academy, Russia
}

Dear participants at the conference!

I am from Saint-Petersburg state academy for engineering and economics.

I am sorry that my English is not very good. But I am hope you will understand..

The department of the municipal economy of this academy, which I represent, carries out different scientific studies: such as housing economics, project management of the municipal energetic, city environment and others. Today we will consider the municipal solid waste management.

This is one of the most important problems in our cities as it is a part of ecological safety for the city dwellers.

I will consider the following questions:

1. Evaluation of the current situation in Russia

2. Purposes and problems of the project

3. Methodology

4. Strategic approach to complex system of the solid waste management

5. Economic mechanism of the system

\section{Evaluation of the current situation in Russia}

In the cities of Russian actual of the solid waste was formed in the soviet time and does not correspond with modern day.

Now in cities the solid waste collection is made without the separating. Plastic, metal, papers and others fraction is collected all together.

The schedule of waste transportation is constantly disrupted.

Waste transportation is produced without transfer stations.

The whole volume of waste is transported to landfills, which do not correspond to the sanitary requirements. Besides, there are multiplied illegal dumps, greatly worsening sanitary condition of territory.

Less than $3 \%$ waste of the country is treated. In some large cities (Moscow, Saint Petersburg and others) part of the waste is treatment or burn on special enterprises, but using of secondary resources is not organized.

Sanitary condition of housing territory and places of temporary storage of MSW is also sanitary non-satisfactory. Wide part of population practically does not have ecological culture of behavior. 


\section{Purposes and tasks of the project}

The main purpose of the project consists in the concept development of the complex management system for MSW in the city.

Other purposes are following:

- increasing population living standards as a result of management system;

- rising economic efficiency of the municipal SWM.

Primary tasks of the project are:

- evaluation of procession of MSW, including matters of collection, transportation, conversions and landfilling of waste;

- development of the main principles and methods for MSW managementi;

- creation and development of complex management system of MSW in the city;

- development of economic mechanism for formation and operation of complex management system of MSW;

- preparation of personnel training program for discipline "Economy and management of MSW in the city".

\section{Methodology}

Main efforts of the complex system of MSW are to be direct on reduction and maximum secondary using of waste, not on the struggle with their consequences.

The main principles of the system development are the following:

- systemization

- integration

- open for the participant processing

- minimization of waste quantity

- purposefulness

- efficiency

- responsibility for paying

- accessibility

- consensus of different interests.

The most important methods of creation and system operations are the following:

1. Technological - organization of MSW collection on the base of selection of the main components (separate collection of waste), transportation of waste with the transfer stations, using the modern technologies of conversion and incineration of waste, organization of using the secondary resources, compost and energy, creation of waste landfilling, which will answer to ecological requirements and the others.

2. Economic - forming of the economic mechanism for the system operation, ensuring organization of financial flows and stimulation for all participants of the process of MSW control.

3. Social - constant propaganda and advertisement for safe ecological and economic efficient ways of production and using waste for population and employs of the organizations of the city.

\section{Strategic approach to complex system of solid waste management in the city}

The most important aim of creation and operation of complex management system for MSW in the city is increasing of population quality live by the way of perfecting a living level, health of inhabitants and lifestyle of people. 
Our approach is the following:

1. Warning and reduction of waste production

2. Organization of the separate collection and transportation of waste.

3. Maximum ust of the secondary resources by sorting, treatment and incineration of waste.

4. Landfilling of the waste part with the account of ecological safety requirements.

Key question in complex management system for MSW is the using of real payment for waste salvaging. Producer of waste must pay in the amount, cover real costs to salvaging.

Main stages of forming complex management system for MSW are the followings:

Firstly - Evaluation of situations and revealing of the real problems in the turning and salvaging of MSW in the city and in the region.

Secondly - Production of the concrete aims and tasks of MSW

Next - Consideration and choice of the variants of forming and operation of the system

Then - Determination of guidelines and actions on creation complex management system for MSW.

Finally - Development of ensuring subsystems.

Forming of the complex management system for MSW in the city is presented by a target block development, forming organizing-management block, development of economic mechanism of system operation and ensuring subsystems. The most important actions on each guideline are the followings: 
The guidelines and actions on creation MSW system

\begin{tabular}{|c|c|}
\hline Guidelines & Actions \\
\hline $\begin{array}{l}\text { 1. Development of the system } \\
\text { target block }\end{array}$ & $\begin{array}{l}\text { 1.1. Development and creation the town standards for sanitary } \\
\text { contents of the city territory. } \\
\text { 1.2. Forming a target installation system and factors with their } \\
\text { quantitative evaluation. } \\
\text { 1.3. Development of complex of tasks, decided in process of } \\
\text { complex control MSW. }\end{array}$ \\
\hline $\begin{array}{l}\text { 2.Creation of the } \\
\text { organizational and } \\
\text { management block }\end{array}$ & $\begin{array}{l}\text { 2.1. Organization of interdepartmental town structure on control } \\
\text { MSW with the participation of all concerned parties } \\
\text { 2.2. Elaboration of organizing procedure on creation and } \\
\text { realization of the system. }\end{array}$ \\
\hline $\begin{array}{l}\text { 3. Elaboration of the program } \\
\text { block }\end{array}$ & $\begin{array}{l}\text { 3.1. Elaboration of the program for collection MSW in built-up } \\
\text { area of the city. } \\
\text { 3.2. Development of the program for construction and } \\
\text { reconstruction of enterprises on conversion and MSW } \\
\text { incineration. } \\
\text { 3.3. Development of the program of erecting a landfills. } \\
\text { 3.4. Development of the program for erecting the transshipment } \\
\text { stations and other program documents }\end{array}$ \\
\hline $\begin{array}{l}\text { 4. Development of the } \\
\text { economic mechanism for } \\
\text { forming and functioning of } \\
\text { the system: }\end{array}$ & $\begin{array}{l}\text { 4.1. Scheduling a system of economic relations for all participants } \\
\text { of the process. } \\
\text { 4.2. Development of the tariff system on the transportation, } \\
\text { conversion, incineration, landfilling and MSW using }\end{array}$ \\
\hline $\begin{array}{l}\text { 5. Development of ensuring } \\
\text { subsystems }\end{array}$ & $\begin{array}{l}\text { 5.1. Legal provision. } \\
\text { 5.2. Financial and investment provision. } \\
\text { 5.3. Technical provision. } \\
\text { 5.4. Information ensuring. } \\
\text { 5.5. Trained ensuring system. } \\
\text { 5.6. Social and psychological ensuring system and others }\end{array}$ \\
\hline
\end{tabular}


..One of the most important conditions of success is a finding of rapport with the wide sections of population for organization of selective collection of waste and for the ecological culture of behavior on work and at home.

And finally I will speak about Economic mechanism of the system

\section{Economic mechanism of the system}

The most important factor of viability of complex managerial system MSW in the city is an economic mechanism of its operation. It is necessary to build such relation system, which will force all participants of management process to act with the account as own, so and public interests. The composition of management process participants is the following:

- organs an authorities and city control - executive and representative organs of authorities and control, forming and using the budget and defining directions of budgetary expenses.

- producers of waste, who present MSW system service users, it may be the city population and organizations;

- - management firm - which executes the main functions for organization and financing of MSW management process;

- companies-producers of services in the MSW sphere - organizations, which execute concrete transport and repair services, works in the preliminary conversion of MSWi;

- - the companies-users of secondary resources, including users cheeses, compost and energy;

- - plants for incineration and MSW treatment;

- landfills;

- investors. 
Scheme of participants relations is presented on the picture.

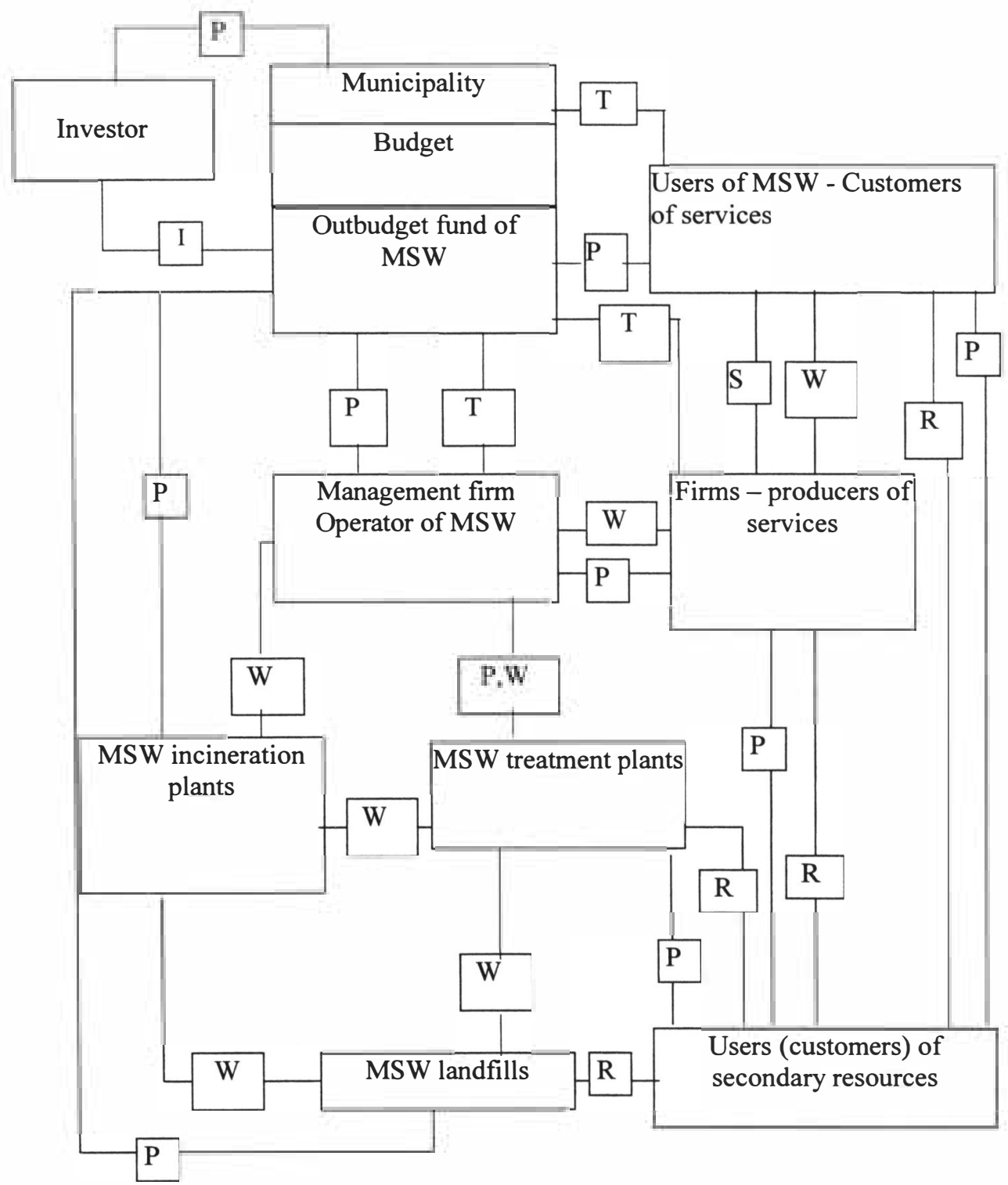

Picture 1. Scheme of material and financial flows 
Indications: $\mathrm{P}$ - payments for work, resources, credits; $\mathrm{S}$ - services for users (acceptance and transportation of waste); T - tariffs and taxes; R - secondary facilities; I - investments; W - waste on different treatment stages

\section{Conclusion}

Thus, the existing system of MSW management is inefficient. There is lack of funds for creation of new system. And even if there was enough money, the existing system would not give sufficient results.

Therefore we need a new complex system which will enable our cities to achieve the present purposes and increasing population living standards.

We hope to continue this work in the framework of scientific studies and during the educational process. Our project creates the system of preparation and refresher course for personnel in the field of municipal solid waste management in Russian cities for speciality 060815 "Municipal economy and management" on the base of Saint-Petersburg State Academy for engineering and economics. 